\title{
Article
}

\section{Analysis of a Resonant Converter with Wide Input Voltage}

\author{
Bor-Ren Lin ${ }^{1, *}$, Alexis Phaik Imm Goh ${ }^{2}$ and Kai-Wei Wang ${ }^{1}$ \\ 1 Department of Electrical Engineering, National Yunlin University of Science and Technology, \\ Yunlin 640, Taiwan; qwe8262878@gmail.com \\ 2 College of Future, National Yunlin University of Science and Technology, Yunlin 640, Taiwan; \\ alexisg@yuntech.edu.tw \\ * Correspondence: linbr@yuntech.edu.tw
}

\section{check for}

updates

Citation: Lin, B.-R.; Goh, A.P.I.; Wang, K.-W. Analysis of a Resonant Converter with Wide Input Voltage. Electronics 2021, 10, 1110. https:/ / doi.org/10.3390/electronics10091110

Academic Editor: Khaled Ahmed

Received: 24 April 2021

Accepted: 4 May 2021

Published: 8 May 2021

Publisher's Note: MDPI stays neutral with regard to jurisdictional claims in published maps and institutional affiliations.

Copyright: (c) 2021 by the authors. Licensee MDPI, Basel, Switzerland. This article is an open access article distributed under the terms and conditions of the Creative Commons Attribution (CC BY) license (https:// creativecommons.org/licenses/by/ $4.0 /)$.

\begin{abstract}
A DC-DC converter with a $16: 1\left(V_{\text {in, } \max }=16 V_{\text {in, min }}\right)$ wide input voltage operation is presented for auxiliary power supplies on solar power conversion circuits or railway vehicles. The solar cell output voltage is associated with the solar intensity (day or night) and geographical location. Thus, the wide input voltage capability of DC converters is required for photovoltaic power conversion. For low power supplies on railway vehicles, the nominal input voltages are $24 \mathrm{~V} \sim 110 \mathrm{~V}$ for the electric door system, motor drive, solid state lighting systems and braking systems. The presented converter uses buck/boost and resonant circuits to achieve the wide input voltage range operation from $18 \mathrm{~V}$ to $288 \mathrm{~V}$. If $V_{\text {in }}$ stays on a low input voltage range $(18 \mathrm{~V} \sim 72 \mathrm{~V})$, the buck/boost circuit is operated at a voltage boost characteristic. On the other hand, the buck/boost circuit is operated at a voltage buck characteristic when the input voltage climbs to a high voltage range $(72 \mathrm{~V} 288 \mathrm{~V})$. Thus, the buck/boost circuit can output a constant voltage. Then, the resonant circuit in the second stage is worked at a constant input voltage case so that the frequency variation range is reduced. Finally, to investigate the performance and effectiveness of the studied circuit, experiments with a $500 \mathrm{~W}$ prototype were conducted to investigate the performance of the studied circuit.
\end{abstract}

Keywords: buck/boost converter; resonant converter; wide input voltage variation

\section{Introduction}

Wide voltage range DC-DC converters have been discussed and presented for solar cell power conversion due to the variable output voltage of the photovoltaic panel. The output voltage of a photovoltaic panel depends on the solar intensity of the day and night. Therefore, DC converters with a wide voltage range are developed for solar power conversion and the self-supplying power units are developed for remote control systems. Wide voltage DC-DC converters are also needed on a railway vehicle due to many different nominal DC voltages $(24 \mathrm{~V} \sim 110 \mathrm{~V})$ that are requested for the communication system, lighting system, electric door system and braking system. Thus, pulse-width modulation (PWM) converters with a wide voltage operation are welcomed and demanded on railway power supply units. Multi-stage converters $[1,2]$ have been proposed to actualize the wide voltage capability operation. The buck or boost circuit topology is selected on the front-stage to achieve a buck or boost operation. The flyback, forward or half-bridge circuit topology with pulse-width modulation is adopted on the rear-stage to regulate output voltage. However, these solutions have high switching losses on power devices and the input voltage range is still limited at $V_{\text {in, } \max } \leq 4 V_{\text {in, } \min }$ or $V_{\text {in, max }} \leq 6 V_{\text {in, min }}$. Seriesparallel connection DC converters have been discussed in [3-5]. Unfortunately, the circuit structure is too complicated and more expensive for use in low or medium power supplies. Single-stage DC converters with a PWM operation were discussed in [6-12] to extend the input voltage range. However, the input voltage range in [6-12] is still limited at $V_{\text {in,max }} \leq 4 V_{\text {in,min }}$. In [13], the thermal constraints issue has been discussed for a currentmode monolithic DC-DC converter. 
In this paper, we present and investigate a DC-DC converter that has a $16: 1$ $\left(V_{\text {in }}=288 \mathrm{~V} \sim 18 \mathrm{~V}\right)$ wide voltage operation and soft switching turn-on operation. To realize a 16:1 wide voltage operation, a buck/boost DC-DC circuit is utilized in the first stage to accomplish either a voltage boost action if the $V_{\text {in }}$ is on a low input voltage range ( $V_{\text {in,min }}<V_{\text {in }}<4 V_{\text {in,min }}$ ) or a voltage buck action if the $V_{\text {in }}$ is on a high input voltage range $\left(4 V_{\text {in, } \min }<V_{\text {in }}<16 V_{\text {in,min }}\right)$. Therefore, the output terminal voltage of the buck/boost converter is controlled at a constant value. An $L L C$ converter is used in the rear-stage to control the output voltage while accomplishing zero voltage switching (ZVS) for active devices. Since the input voltage of the LLC converter is almost constant due to the buck/boost converter regulation, the variation in switching frequency is limited to a narrow frequency range. Compared to conventional DC-DC converters and multi-stage converters, the main contributions in this paper are (1) the wide voltage range action, (2) the soft switching operation in the second stage circuit, and (3) the simple control scheme. The converter characteristics are confirmed by the experiments using a prototype circuit.

\section{Circuit Structure}

Figure 1 provides the circuit schematic of the presented PWM converter with the function of a 16:1 voltage range operation for PV panel power converters or the auxiliary power on railway vehicles. The presented circuit is a two-stage DC converter. The frontstage is a buck/boost circuit and the rear-stage is an LLC converter. The components of a buck/boost circuit include $Q_{1}, D_{1}, L_{f}, Q_{2}, D_{2}$ and $C_{d c}$. The $L L C$ converter includes $L_{r}$, $S_{1}, S_{2}, T, C_{r}, D_{\mathrm{o} 1}, D_{\mathrm{o} 2}$ and $C_{o}$. The buck/boost circuit can achieve a wide input voltage range operation. When $V_{i n}<V_{d c}$, the buck/boost circuit is operated at a voltage boost. On the other hand, the buck/boost circuit is worked at a buck operation if $V_{\text {in }}>V_{d c}$. The $L L C$ resonant circuit in the rear-stage is operated at a constant input voltage $V_{d c}$ condition. Therefore, the switching frequency of a resonant circuit can be designed at a series resonant frequency to lessen the magnetizing current losses, while, at the same time, having ZVS characteristics for switches $S_{1}$ and $S_{2}$ and diodes $D_{01}$ and $D_{o 2}$. According to the input voltage range, the presented converter can be operated at two voltage ranges $\left(V_{\text {in, } \min } \sim 4 V_{\text {in,min }}\right)$ and $\left(4 V_{\text {in,min }} \sim 16 V_{\text {in, min }}\right)$. When $V_{\text {in }}$ is greater than $V_{\text {in,min }}$ and less than $4 V_{\text {in,min }}$, the switch $Q_{1}$ is on, diode $D_{1}$ is on the reverse biased and $Q_{2}$ is controlled with pulse-width modulation. Thus, the buck/boost circuit is worked like a boost converter to achieve a voltage step-up characteristic, as shown in Figure $2 \mathrm{a}$. The DC bus voltage $V_{d c}$ is controlled at the reference voltage $V_{d c, r e f}$ and the $L L C$ resonant circuit is controlled at a constant input voltage case. When $4 V_{\text {in, min }}<V_{\text {in }}<16 V_{\text {in, min }}$, switch $Q_{2}$ is off and switch $Q_{1}$ is controlled with a pulse-width modulation scheme to control the DC bus voltage $V_{d c}=V_{d c, r e f}$. Thus, the buck/boost converter is working as a buck converter to achieve a voltage step-down characteristic, as shown in Figure $2 b$. According to the adopted control algorithm, the studied converter has a 16:1 $\left(V_{\text {in,max }}=16 V_{i n, \min }\right)$ voltage range operation for a solar PV panel power conversion and a railway vehicle with low power supplies and applications.

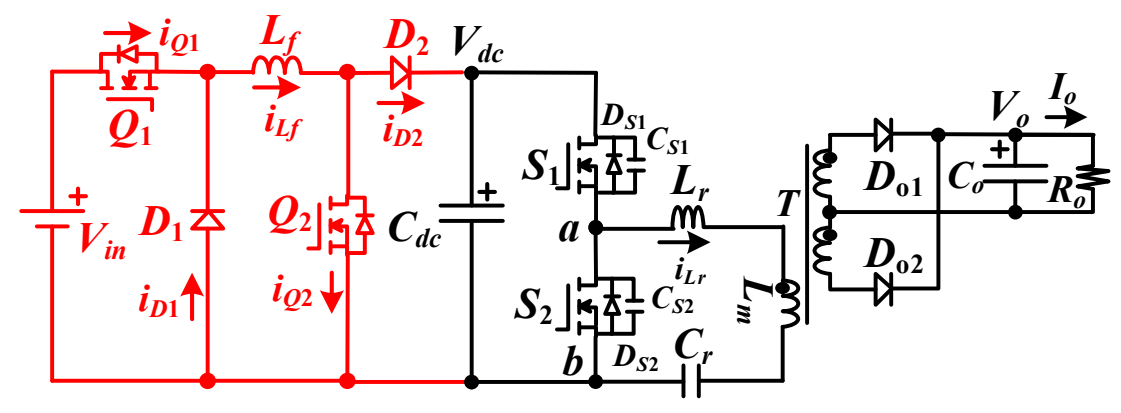

Figure 1. The circuit diagram of the presented converter with $16: 1\left(V_{i n, \max }=16 V_{\text {in, } \min }\right)$ voltage range operation. 


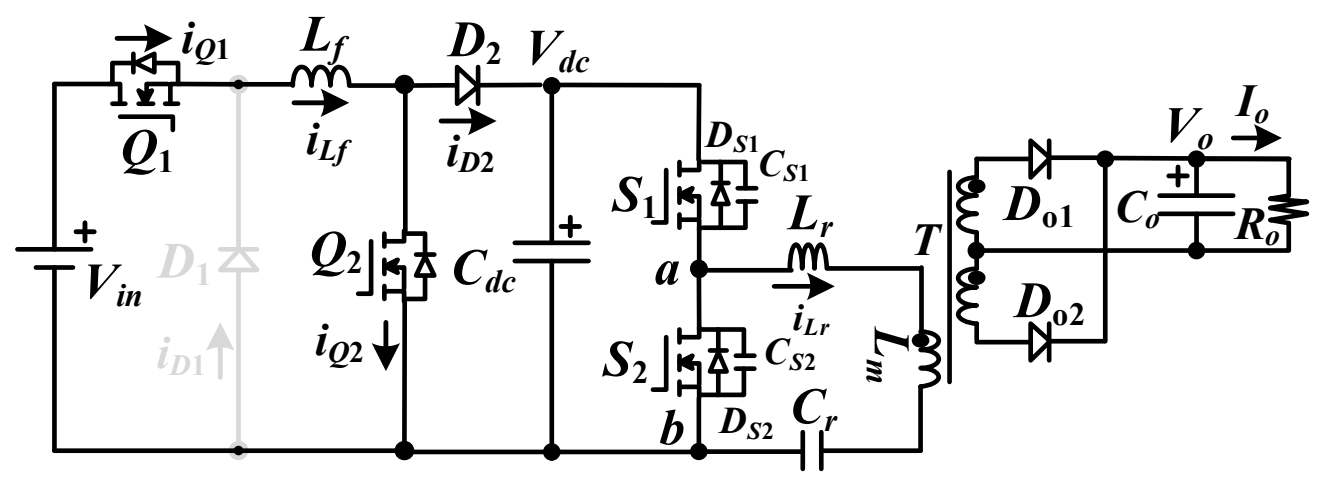

(a)

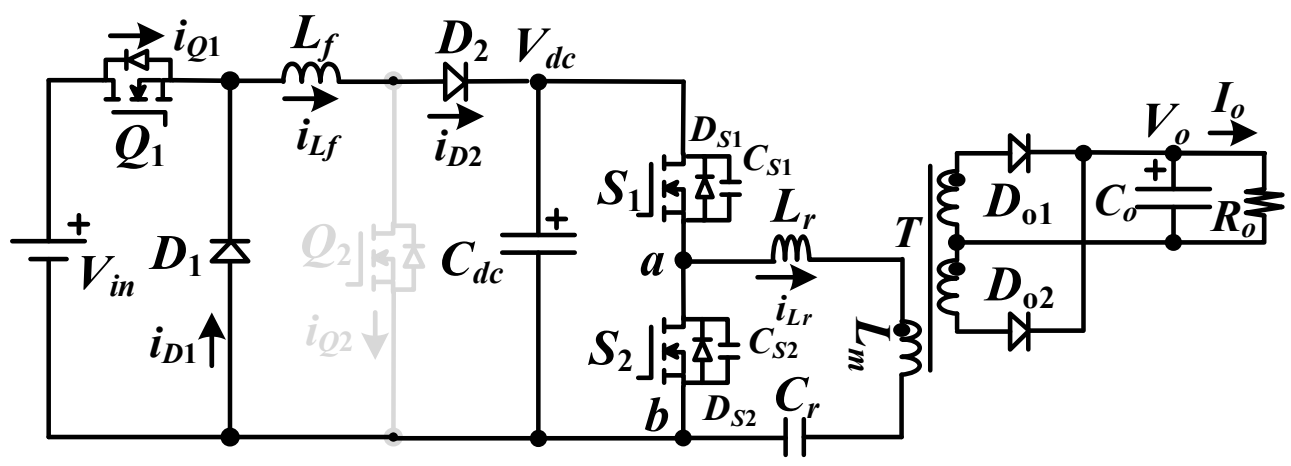

(b)

Figure 2. Equivalent circuits for (a) low input voltage operation (b) high input voltage operation.

\section{Operation Principle}

The studied converter is a two-stage circuit. The front-stage is a buck/boost converter to achieve either a voltage boost action if $V_{\text {in }}$ is on a low input voltage range or a voltage buck action if $V_{\text {in }}$ is on a high input voltage range. The buck/boost converter is regulated by a pulse-width modulation. The second stage is an $L L C$ resonant converter to accomplish both electric isolation and a ZVS turn-on operation for active devices.

\subsection{Circuit Operation of the Buck/Boost Converter}

The buck/boost converter can work at a voltage boost operation or buck operation. To accomplish a wide voltage operation, the DC bus voltage of the buck/boost converter is controlled at $V_{d c}=4 V_{i n, \text { min }}$. When $V_{\text {in, } \min } \leq V_{\text {in }}<4 V_{\text {in, min }}$, the buck/boost converter operates at a boost operation (Figure 2a)and $Q_{1}$ is on, diode $D_{1}$ is off and $Q_{2}$ is controlled by a pulsewidth modulation to have a voltage boost action. Figure 3 a gives the PWM signals of the buck/boost converter for a voltage step-up action. Under a continuous conduction mode operation, two circuit modes are observed (Figure $3 b, c)$. Based on a voltage-second balance on the inductor $L_{f}$, the DC bus voltage $V_{d c}$ is obtained as $d_{Q 1} V_{\text {in }} /\left(1-d_{Q 2}\right)=V_{\text {in }} /\left(1-d_{Q 2}\right)$ where $d_{Q 1}$ and $d_{Q 2}$ are duty cycles of $Q_{1}$ and $Q_{2}$, respectively, and $d_{Q 1}=1$ under the boost operation.

Mode $1\left[t_{0} \sim t_{0}+d_{Q 2} T_{s w}\right]$ : At $t=t_{0}, Q_{2}$ is activated to turn on. Since $Q_{1}$ is always on and $D_{1}$ is reverse biased for the voltage boost operation, the voltage across on $L_{f}$ can be obtained as $v_{L f}=V_{\text {in }}$ and $v_{D 2}$ is $-V_{D C}$. The inductor current $i_{L f}$ increases and the diode $D_{2}$ is reverse biased. Capacitor $C_{d c}$ is discharged to supply current $i_{d c}$ to the secondstage resonant converter. 


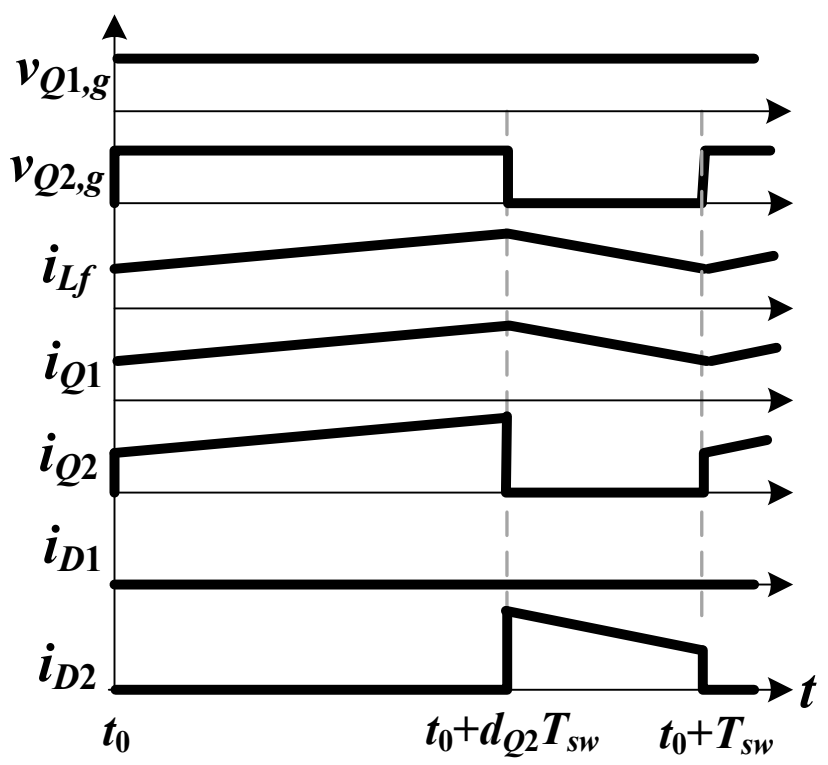

(a)

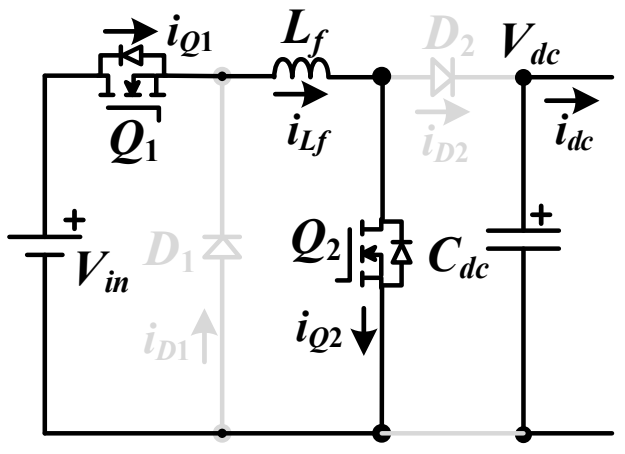

(b)

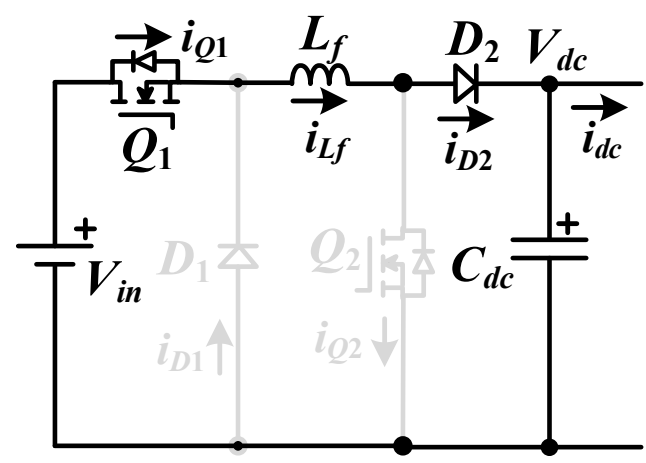

(c)

Figure 3. Buck/boost converter under low voltage range (boost operation) (a) pulse-width modulation (PWM) signals (b) mode 1 equivalent circuit (c) mode 2 equivalent circuit.

Mode $2\left[t_{0}+d_{Q 2} T_{s w} \sim t_{0}+T_{s w}\right]$ : At $t=t_{0}+d_{Q 2} T_{s w}, Q_{2}$ is turned off. The inductor $i_{L f}$ flows through $D_{2}$ to charge $C_{d c}$. The inductor voltage $v_{L f}=V_{i n}-V_{d c}<0$ so that $i_{L f}$ decreases. The drain-to-source voltage of $Q_{2}$ is equal to the DC bus voltage $V_{d c}$. Mode 2 is ended at time $t_{0}+T_{s w}$.

When $4 V_{\text {in, } \min }<V_{\text {in }} \leq 16 V_{\text {in,min }}$, the buck/boost converter operates as a voltage step-down operation (Figure $2 \mathrm{~b}$ ). The switch $Q_{2}$ is controlled at an off state, diode $D_{2}$ is always conducting and $Q_{1}$ is activated by pulse-width modulation to accomplish a voltage step-down. The pulse-width modulation waveforms of the voltage step-down operation are given in Figure $4 \mathrm{a}$ and two circuit modes are shown in Figure $4 \mathrm{~b}, \mathrm{c}$ under a 
continuous conduction mode. Based on a flux balance on inductor $L_{f}$, the DC bus voltage $V_{d c}$ is calculated as $d_{Q 1} V_{i n} /\left(1-d_{Q 2}\right)=d_{Q 1} V_{\text {in }}$ where $d_{Q 2}=0$ under the buck operation.

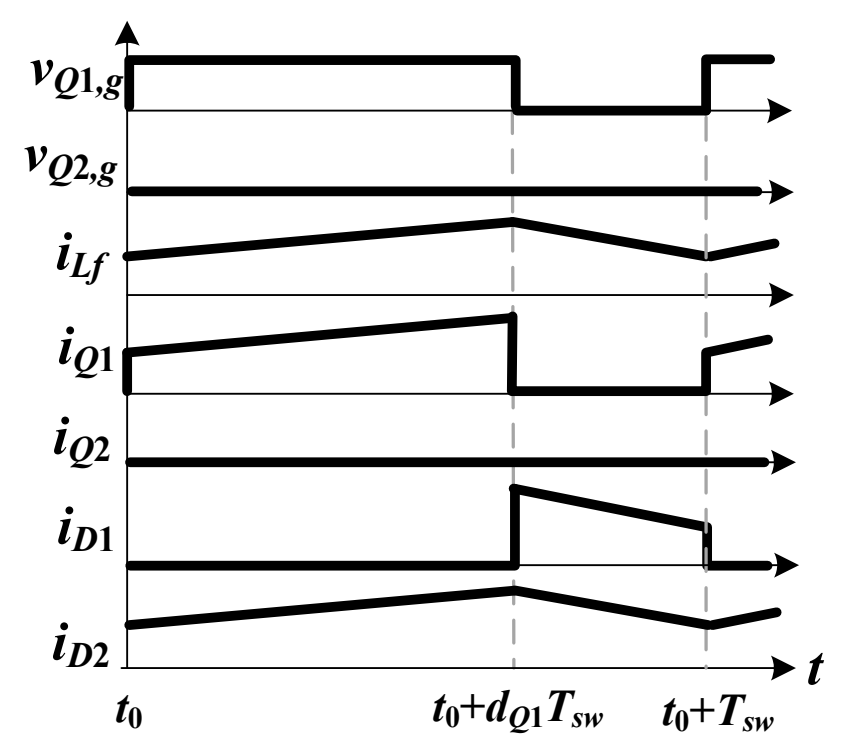

(a)

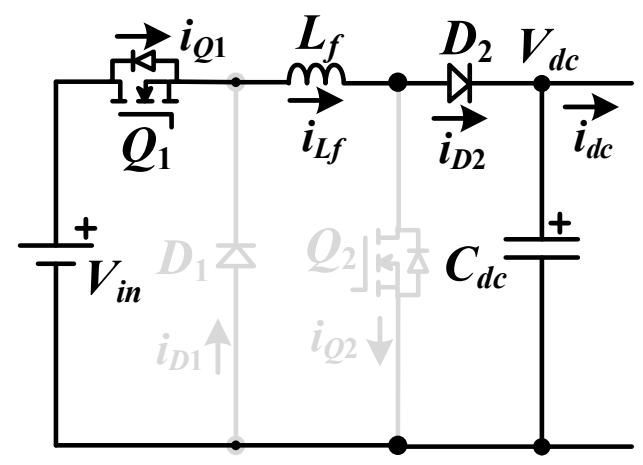

(b)

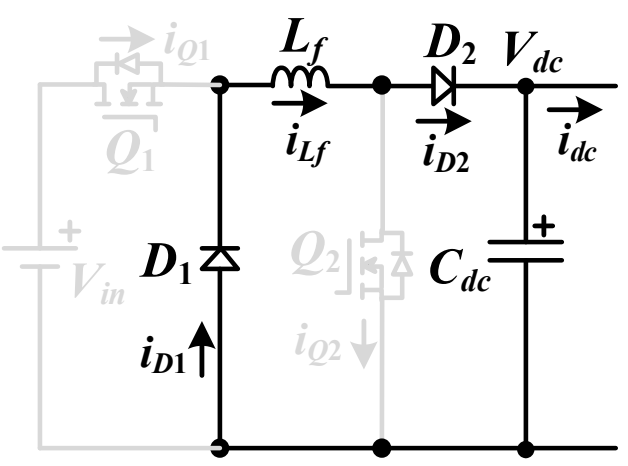

(c)

Figure 4. Buck/boost converter under high voltage range (buck operation) (a) PWM signals (b) mode 1 equivalent circuit (c) mode 2 equivalent circuit.

Mode $1\left[t_{0} \sim t_{0}+d_{Q 1} T_{s w}\right.$ ]: At time $t_{0}, Q_{1}$ turns on. Since $Q_{2}$ is always off and $D_{2}$ is forward biased for the voltage step-down operation, the inductor voltage $v_{L f}=V_{i n}-V_{d c}>0$ and $v_{D 1}$ is $-V_{i n}$. In this mode, $i_{L f}$ increases, the $D_{1}$ is reverse biased and $C_{d c}$ is charged.

Mode $2\left[t_{0}+d_{Q 1} T_{s w} \sim t_{0}+T_{s w}\right]$ : At time $t_{0}+d_{Q 1} T_{s w}, Q_{1}$ turns off. In mode 2, $v_{L f}=-V_{d c}, \mathrm{i}_{\mathrm{Lf}}$ decreases, $v_{\mathrm{Q} 1, d s}=V_{i n}, v_{\mathrm{Q} 2, d s}=V_{d c}$ and $C_{d c}$ is discharged. This mode ends at time $t_{0}+T_{s w}$. 


\subsection{Circuit Operation of the LLC Resonant Circuit}

Since the DC bus voltage $V_{d c}$ is a constant voltage due to the buck/boost circuit operation, the $L L C$ resonant converter is operated under almost constant voltage $V_{d c}$. Thus, the switching frequency of the $L L C$ resonant circuit is controlled at a limited narrow frequency range. The converter voltage gain is calculated as $G_{L L C}=2 n V_{o} / V_{d c}=2 n V_{o}$ $\left(1-d_{Q 2}\right) / d_{Q 1} V_{i n}$. Figure 5 a gives the main circuit waveforms of the resonant converter and Figure $5 \mathrm{~b}-\mathrm{g}$ shows the six mode operations.

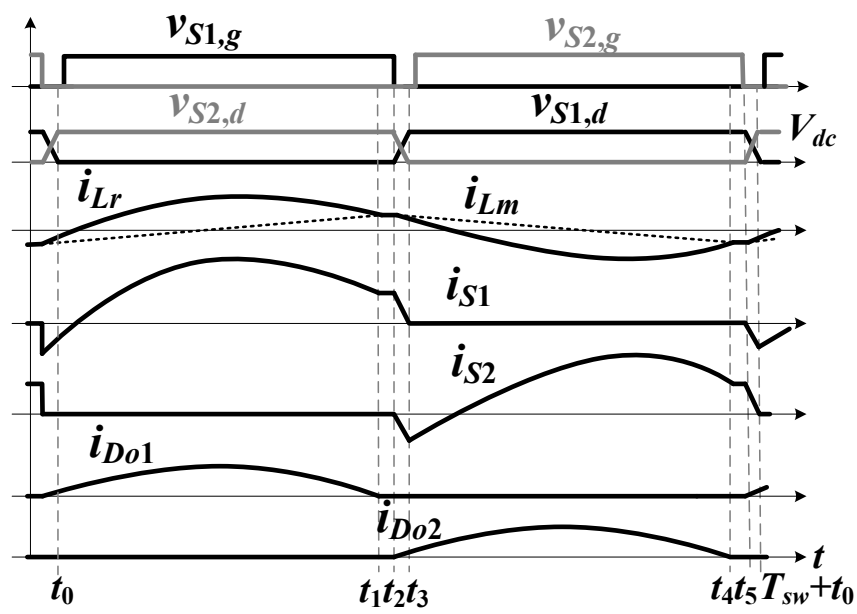

(a)

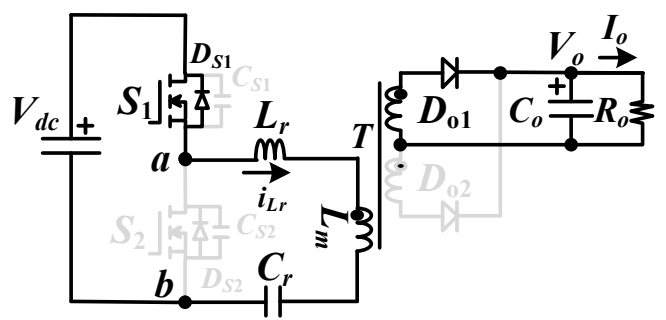

(b)

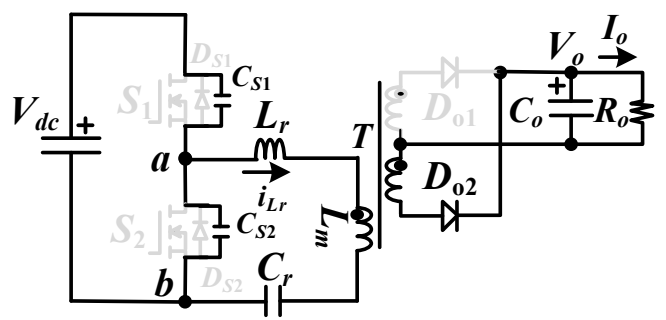

(d)

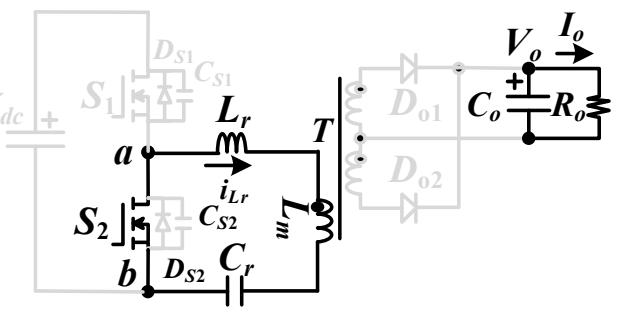

(f)

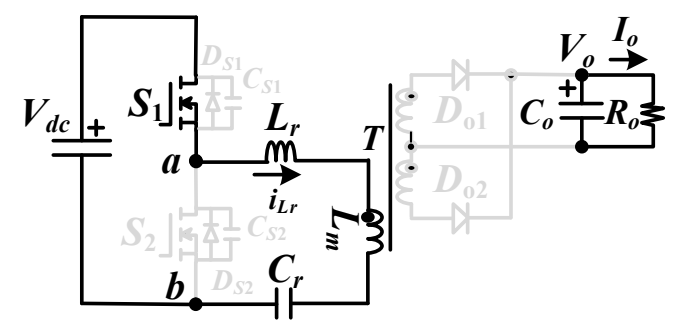

(c)

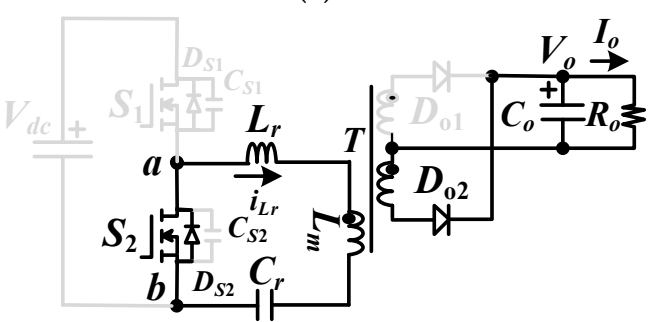

(e)

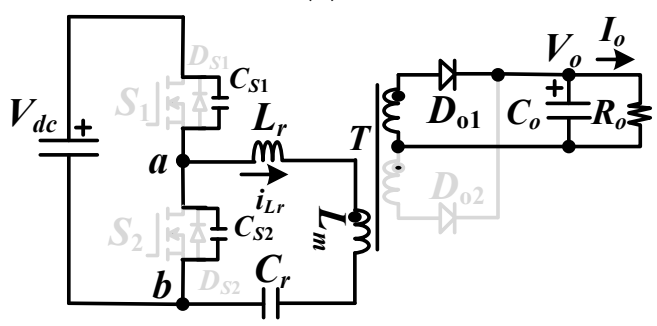

(g)

Figure 5. Circuit operations of resonant converter (a) PWM signals (b) mode 1 equivalent circuit (c) mode 2 equivalent circuit (d) mode 3 equivalent circuit (e) mode 4 equivalent circuit (f) mode 5 equivalent circuit (g) mode 6 equivalent circuit. 
Mode $1\left[t_{0} \sim t_{1}\right]$ : At time $t<t_{0}$, the active device $S_{1}$ is off, $v_{C S 1}$ is positive and $i_{L r}$ is negative. At time $t_{0}, v_{C S 1}=0$ and $D_{S 1}$ is conducting. After time $t_{0}, S_{1}$ can turn on at the ZVS action. Since $D_{o 1}$ is conducting, $v_{L m}=n V_{o}$. Power is delivered to a load side through the components $S_{1}, L_{r}, T, C_{r}$ and $D_{o 1} . L_{r}$ and $C_{r}$ are naturally resonant, with frequency $f_{r}=1 / 2 \pi \sqrt{L_{r} C_{r}}$. If $f_{r}$ is greater than the switching frequency $f_{s w}$, then the circuit proceeds to mode 2 , or it goes to mode 3 .

Mode 2 [t $\left.t_{1} \sim t_{2}\right]$ : Since $f_{r}>f_{s w}, i_{D o 1}$ will decrease to 0 at $t_{1} . D_{o 1}$ is off. $i_{L r}$ will flow through $S_{1}, L_{m}, L_{r}$ and $C_{r}$. Together with $L_{r}$ and $L_{m}, C_{r}$ is naturally resonant, with frequency $f_{m}=1 / 2 \pi \sqrt{\left(L_{m}+L_{r}\right) C_{r}}$ and $f_{m}<f_{r}$.

Mode $3\left[t_{2} \sim t_{3}\right]$ : Active device $S_{1}$ is turned off at time $t_{2}$ under zero voltage. After time $t_{2}, i_{L r}>0$ and $i_{L r}<i_{L m}$. Thus, $C_{S 2}\left(C_{S 1}\right)$ discharges (charges) and the secondary diode $D_{02}$ conducts.

Mode $4\left[t_{3} \sim t_{4}\right]$ : At time $t_{3}, C_{S 2}$ is discharged to zero and $D_{S 2}$ is conducting due to $i_{L r}\left(t_{3}\right)>0$. After $t_{3}, S_{2}$ turns on under zero voltage. $D_{o 2}$ is forward biased on the secondary side, $v_{L m}=-n V_{o}$. Energy stored on $C_{r}$ is transferred to the output load. $L_{r}$ and $C_{r}$ are naturally resonant, with frequency $f_{r}$.

Mode $5\left[t_{4} \sim t_{5}\right]$ : If $f_{s w}<f_{r}$, then $i_{D 2}$ will decrease to 0 at $t_{4} . D_{o 2}$ is reverse biased. No power is delivered to the output load. $L_{r}, L_{m}$ and $C_{r}$ are naturally resonant, with frequency $f_{m}$.

Mode $6\left[t_{5} \sim T_{s w}+t_{0}\right]: S_{2}$ turns off at time $t_{5} . C_{S 1}\left(C_{S 2}\right)$ discharges (charges) and $D_{o 1}$ conducts because the $i_{L r}\left(t_{5}\right)<0$ and $i_{L r}\left(t_{5}\right)>i_{L m}\left(t_{5}\right)$. Mode 6 ends at time $T_{s w}+t_{0}$.

\section{Circuit Characteristics}

The buck/boost converter is operated by a 16:1 wide voltage range operation. The output voltage $V_{d c}$ of the buck/boost converter is controlled at $V_{d c, r e f}=4 V_{\text {in,min }}$. If $V_{\text {in }}$ is on a low voltage range $\left(V_{i n}<V_{d c, r e f}=4 V_{i n, m i n}\right)$, then the converter is operated at the boost operation. As a result, $Q_{1}$ stays on, $Q_{2}$ is operated by a duty cycle control and $D_{1}$ is reverse biased. When $V_{i n}$ is on a high input voltage range $\left(V_{i n}>V_{d c, r e f}=4 V_{i n, m i n}\right)$, the converter is operated at a buck operation. As a result, $Q_{2}$ stays off and $Q_{1}$ is operated by pulse-width modulation. Thus, the $L L C$ resonant circuit is operated at a constant input voltage of $V_{d c}$ $=4 V_{\text {in, } \min }$. The buck/boost converter is controlled at a continuous conduction mode. For the boost operation, $V_{L f}=V_{\text {in }}$ (or $V_{\text {in }}-V_{o}$ ) if $Q_{2}$ is on (or off) as shown in Figure 3. For the buck operation, $V_{L f}=V_{\text {in }}-V_{o}$ (or $-V_{o}$ ) if $Q_{1}$ is on (or off) as shown in Figure 4 . For a continuous conduction mode, the DC bus voltage $V_{d c}$ is calculated as:

$$
V_{d c}=\left\{\begin{array}{cl}
V_{i n} /\left(1-d_{Q 2}\right), & V_{i n}<V_{d c, r e f}=4 V_{\text {in,min }} \\
d_{Q 1} V_{i n}, & V_{i n}>V_{d c, \text { ref }}=4 V_{\text {in,min }}
\end{array}\right.
$$

where $d_{Q 1}$ and $d_{Q 2}$ are duty cycles of $Q_{1}$ and $Q_{2}$, respectively. $V_{\text {in }}$ is greater than $V_{\text {in, } \min }$ and less than $4 V_{i n, m i n}$ on the low voltage range. Therefore, the maximum and minimum duty cycles of $Q_{2}$ are expressed as:

$$
\begin{aligned}
& d_{Q 2, \text { max }}=\left(V_{d c, \text { ref }}-V_{\text {in, } \text { min }}\right) / V_{d c, \text { ref }} \\
& d_{Q 2, \text { min }}=\left(V_{d c, \text { ref }}-4 V_{\text {in, min }}\right) / V_{d c, \text { ref }}
\end{aligned}
$$

In the same manner, the maximum and minimum duty cycles of $Q_{1}$ are expressed as (4) and (5) on the high input voltage range $\left(4 V_{\text {in, min }}<V_{\text {in }}<16 V_{\text {in, min }}\right)$.

$$
\begin{aligned}
& d_{Q 1, \text { max }}=V_{d c, \text { ref }} / 4 V_{i n, \text { min }} \\
& d_{Q 1, \text { min }}=V_{d c, \text { ref }} / 16 V_{i n, \text { min }}
\end{aligned}
$$


If the DC bus current and $d_{Q 1}$ and $d_{Q 2}$ are given, then the root mean square (rms) currents $I_{Q 1, r m s}$ and $I_{Q 2, r m s}$ are obtained in (6) and (7).

$$
\begin{aligned}
& I_{Q 1, r m s}=\left\{\begin{array}{cc}
I_{d c} /\left(1-d_{Q 2}\right), & V_{i n}<V_{d c, r e f}=4 V_{i n, \text { min }} \\
\sqrt{d_{Q 1}} I_{d c}, & V_{i n}>V_{d c, \text { ref }}=4 V_{i n, \text { min }}
\end{array}\right. \\
& I_{Q 2, r m s}=\left\{\begin{array}{cl}
I_{d c} \sqrt{d_{Q 2}} /\left(1-d_{Q 2}\right), & V_{i n}<V_{d c, r e f}=4 V_{i n, m i n} \\
0, & V_{\text {in }}>V_{d c, \text { ref }}=4 V_{\text {in, min }}
\end{array}\right.
\end{aligned}
$$

From the on/off states of $Q_{1}, Q_{2}, D_{1}$ and $D_{2}$, the voltage ratings of $Q_{1}$ and $Q_{2}$ are $V_{i n, \max }$ and $V_{d c}$, respectively. The average currents $I_{D 1}$ and $I_{D 2}$ are obtained in (8) and (9).

$$
I_{D 1}=\left\{\begin{array}{cl}
0, & V_{i n}<V_{d c, r e f}=4 V_{i n, \text { min }} \\
\left(1-d_{Q 1}\right) I_{d c}, & V_{\text {in }}>V_{d c, r e f}=4 V_{i n, \text { min }} \\
I_{D 2}=I_{d c}
\end{array}\right.
$$

$V_{i n, \max }$ and $V_{d c}$ are the voltage ratings of $D_{1}$ and $D_{2}$ respectively. Based on the boost or buck operation, the rms inductor current is calculated as:

$$
I_{L f, r m s}=\left\{\begin{array}{cl}
I_{d c} /\left(1-d_{Q 2}\right), & V_{i n}<V_{d c, \text { ref }}=4 V_{\text {in, }, \text { min }} \\
I_{d c}, & V_{\text {in }}>V_{d c, \text { ref }}=4 V_{\text {in, min }}
\end{array}\right.
$$

The half-bridge resonant circuit is controlled with pulse frequency modulation. Since $S_{1}$ and $S_{2}$ have a $50 \%$ duty cycle, a square wave voltage waveform with 0 and $V_{d c}$ is generated on voltage $v_{a b}$. The $r m s$ value of $v_{a b}$ approximates $V_{a b, r m s}=\sqrt{2} V_{d c} / \pi$. According to the conducting states of $D_{o 1}$ and $D_{o 2}$, a square voltage waveform is generated on the magnetizing voltage $v_{L m}$ and $V_{L m, r m s}=2 \sqrt{2} n V_{o} / \pi$. The fundamental primary-side resistance is calculated as $R_{a c}=8 n^{2} R_{o} / \pi^{2}$, where $R_{o}$ is the DC load resistance. Since the resonant tank $\left(L_{m}, C_{r}, L_{r}\right.$ and $\left.R_{a c}\right)$ is adopted in the rear-stage, in (11) the voltage transfer function of the resonant tank is obtained.

$$
\begin{gathered}
\left|G_{L L C}\right|=\frac{V_{L m, r m s}}{V_{a b, r m s}}=\left|\frac{R_{a c} / / j 2 \pi f_{s w} L_{m}}{j 2 \pi f_{s w} L_{r}+\left(j 2 \pi f_{s w} C_{r}\right)^{-1}+R_{a c} / / j 2 \pi f_{s w} L_{m}}\right| \\
=\frac{\left.1+\frac{1}{L_{B}} \frac{f_{n}^{2}-1}{f_{n}^{2}}\right]^{2}+Q^{2}\left[\frac{f_{n}^{2}-1}{f_{n}}\right]^{2}}{V_{d c}}
\end{gathered}
$$

where $L_{B}=L_{m} / L_{r}, Q=\sqrt{L_{r} / C_{r}} / R_{a c}$ and $f_{n}=f_{s w} / f_{r}$. Since the DC bus voltage $V_{d c}$ is regulated at $V_{d c, \text { ref }}$ by the front-stage buck/boost circuit, the switching frequency $f_{s w}$ depends on $I_{0}$ or $R_{o}$. The $L L C$ resonant circuit is controlled at an inductive load. Therefore, active devices of the resonant circuit are operated using a soft switching operation.

\section{Experimental Results}

The studied circuit is tested and investigated to show the performance of the prototype circuit. The prototype is designed under the following specifications: $V_{\text {in }}=288 \mathrm{~V} \sim 18 \mathrm{~V}$ (16:1 ratio), $V_{o}=12 \mathrm{~V}, P_{o, \text { rated }}=500 \mathrm{~W}$ and $f_{r}=60 \mathrm{kHz}$. When $V_{\text {in }}=18 \mathrm{~V} \sim 65 \mathrm{~V}$, the buck $/$ boost converter is controlled at boost operation. The voltage $V_{d c}$ is maintained at $72 \mathrm{~V}$. If the input voltage $V_{\text {in }}=76 \mathrm{~V} \sim 288 \mathrm{~V}$, then the buck/boost converter is operated at a buck operation and the DC bus voltage $V_{d c}=72 \mathrm{~V}$. However, no voltage step-up or step-down is operated on the buck/boost converter when $65 \mathrm{~V}<V_{\text {in }}<76 \mathrm{~V}$. $Q_{1}\left(Q_{2}\right)$ is on (off) under this condition and $V_{d c}=V_{i n}$. Therefore, the resonant circuit is designed under the input of a DC bus voltage $V_{d c}=65 \mathrm{~V} \sim 76 \mathrm{~V}$. Two Schmitt voltage comparators are used to detect the three input voltage ranges $18 \mathrm{~V} \sim 65 \mathrm{~V}, 65 \mathrm{~V} \sim 76 \mathrm{~V}$ and $76 \mathrm{~V} \sim 288 \mathrm{~V}$. If $V_{\text {in }}$ is on a low voltage range 
(18 V $65 \mathrm{~V}), Q_{2}$ is controlled by a duty cycle scheme to achieve a boost operation. The duty cycle of $Q_{2}$ is calculated in (12) and (13) under continuous conduction mode.

$$
\begin{aligned}
& d_{Q 2, \text { min }}=\frac{V_{d c, \text { ref }}-V_{\text {in, high }}}{V_{d c, \text { ref }}}=\frac{72-65}{72} \approx 0.1 \\
& d_{Q 2, \text { max }}=\frac{V_{d c, \text { ref }}-V_{\text {in,low }}}{V_{D C, \text { ref }}}=\frac{72-18}{72} \approx 0.75
\end{aligned}
$$

For a high input voltage range of $76 \mathrm{~V} \sim 288 \mathrm{~V}, Q_{1}$ is controlled by a duty cycle scheme to achieve a buck operation. The duty cycle of $Q_{1}$ is given in (14) and (15) under continuous conduction mode.

$$
\begin{gathered}
d_{Q 1, \text { min }}=\frac{V_{d c, \text { ref }}}{V_{\text {in,high }}}=\frac{72}{288} \approx 0.25 \\
d_{Q 1, \text { max }}=\frac{V_{d c, \text { ref }}}{V_{\text {in,low }}}=\frac{72}{76} \approx 0.95
\end{gathered}
$$

It is assumed that the ripple current $\Delta i_{L f}$ is $5 \%$ of the maximum input current at $18 \mathrm{~V}$ of input voltage. Therefore, inductance $L_{f}$ is given in (16).

$$
L_{f}=\frac{V_{i n, \min } d_{Q 2, \max }}{\Delta i_{L f} f_{s w}}=\frac{18 \times 0.75}{0.04 \times(500 / 18) \times 60 \times 10^{3}} \approx 203 \mu \mathrm{H}
$$

The rms switch currents $I_{Q 1, r m s}$ and the $I_{Q 2, r m s}$ are expressed in (17) and (18).

$$
\begin{aligned}
& I_{Q 1, r m s}=\left\{\begin{array}{c}
\frac{I_{d c}}{1-d_{Q 2, \text { max }}}=\frac{500 / 72}{1-0.75} \approx 28 \mathrm{~A}, 18 \mathrm{~V}<V_{\text {in }}<65 \mathrm{~V} \\
\sqrt{d_{Q 1, \text { max }} I_{d c}}=\sqrt{0.95} \frac{500}{72} \approx 6.8 \mathrm{~A}, 76 \mathrm{~V}<V_{\text {in }}<288 \mathrm{~V}
\end{array}\right. \\
& I_{\mathrm{Q} 2, \mathrm{rms}}=\left\{\begin{array}{c}
\frac{I_{d c} \sqrt{d_{\mathrm{Q} 2, \max }}}{1-d_{\mathrm{Q}, \max }}=\frac{\frac{500}{72} \sqrt{0.75}}{1-0.75} \approx 24,18 \mathrm{~V}<V_{\text {in }}<65 \mathrm{~V} \\
0,76 \mathrm{~V}<V_{\text {in }}<288 \mathrm{~V}
\end{array}\right.
\end{aligned}
$$

The voltage ratings of $Q_{1}$ and $Q_{2}$ are $V_{i n, \max }=288 \mathrm{~V}$ and $V_{d c, \max }=76 \mathrm{~V}$. Switch $Q_{1}$ used two MOSFETs STB35N60DM2 (STMicroelectronics, Geneva, Switzerland) with $600 \mathrm{~V} / 28 \mathrm{~A}$ ratings, while switch $Q_{2}$ adopted MOSFET IRFB4110PbF (Infineon Technologies, Neubiberg, Germany) with $100 \mathrm{~V} / 120$ A ratings. The average diode currents of $D_{1}$ and $D_{2}$ are obtained in (19) and (20).

$$
\begin{gathered}
I_{D 1}=\left\{\begin{array}{cc}
0, & 18 \mathrm{~V}<V_{\text {in }}<65 \mathrm{~V} \\
\left(1-d_{Q 1, \min }\right) I_{d c} \approx 5.2 \mathrm{~A}, & 76 \mathrm{~V}<V_{\text {in }}<288 \mathrm{~V}
\end{array}\right. \\
I_{D 2}=I_{d c}=500 / 72 \approx 7 \mathrm{~A}
\end{gathered}
$$

$D_{1}$ has a voltage stress of $V_{i n, \max }=288 \mathrm{~V}$ and $D_{2}$ has a voltage stress of $V_{d c, \max }=76 \mathrm{~V}$. SF1006G (TSMC, Hsinchu, Taiwan) and STPS20SM100S (STMicroelectronics, Geneva, Switzerland) with $400 \mathrm{~V} / 10 \mathrm{~A}$ and $100 \mathrm{~V} / 20 \mathrm{~A}$ ratings are used for diodes $D_{1}$ and $D_{2}$, respectively.

For the $L L C$ resonant circuit design, the necessary resonant frequency and inductor ratio are selected as $f_{r}=60 \mathrm{kHz}$ and $L_{B}=8$. The minimum, nominal and maximum DC bus voltages are $65 \mathrm{~V}, 72 \mathrm{~V}$ and $76 \mathrm{~V}$, respectively. The nominal voltage gain of $G_{n o m}$ at $V_{d c, n o m}=72 \mathrm{~V}$ is designed at unity. Therefore, the turn-ratio $n$ of the transformer is calculated as follows.

$$
n=\frac{G_{L L C, n o m} V_{d c, n o m}}{2 V_{o}}=\frac{1 \times 72}{2 \times 12} \approx 3
$$


The TDK EER42 with $n_{s}=4$ and $n_{p}=12$ is used for the transformer $T$. Thus, the voltage gains $G_{L L C, \max }$ and $G_{L L C, \min }$ at $V_{d c}=65 \mathrm{~V}$ and $76 \mathrm{~V}$ are calculated in (22) and (23).

$$
\begin{aligned}
& G_{L L C, \text { max }}=\frac{2 n V_{o}}{V_{d c, \text { min }}}=\frac{2 \times 3 \times 12}{65} \approx 1.1 \\
& G_{L L C, \text { min }}=\frac{2 n V_{o}}{V_{d c, \text { max }}}=\frac{2 \times 3 \times 12}{76} \approx 0.95
\end{aligned}
$$

For full rated power, the fundamental primary-side resistance $R_{a c}$ is obtained in (24).

$$
R_{a c}=\frac{8 n^{2} R_{o}}{\pi^{2}}=\frac{8 \times 3^{2} \times\left(12^{2} / 500\right)}{\pi^{2}} \approx 2.1 \Omega
$$

The selected quality factor $Q$ is 0.7 . From the given $Q, R_{a c}$ and $f_{r}$, the resonant inductance $L_{r}$ is obtained as:

$$
L_{r}=\frac{Q R_{a c}}{2 \pi f_{r}}=\frac{0.7 \times 2.1}{2 \pi \times 60000} \approx 3.9 \mu \mathrm{H}
$$

due to $L_{B}=8, L_{m}=L_{B} \times L_{r}=31.2 \mu \mathrm{H}$. $C_{r}$ can be calculated as:

$$
C_{r}=\frac{1}{4 \pi^{2} L_{r} f_{r}^{2}}=\frac{1}{4 \pi^{2} \times 3.9 \times 10^{-6} \times(60000)^{2}} \approx 1.8 \mu \mathrm{F}
$$

The voltage ratings of $S_{1}$ and $S_{2}$ equal $V_{d c, \text { max }}=76 \mathrm{~V}$ and the voltage rating of diodes $D_{01}$ and $D_{o 2}$ equals $2 V_{o}=24 \mathrm{~V}$. Power switches IPP111N15N3 $(150 \mathrm{~V} / 83 \mathrm{~A})$ are adopted for active devices $S_{1}$ and $S_{2}$ and S60SC6M (60 V/60 A) (Shindengen Electric Manufacturing, Tokyo, Japan) switches are selected for $D_{o 1}$ and $D_{o 2}$. The selected $C_{d c}=680 \mu \mathrm{F}$ and $C_{o}=1000 \mu \mathrm{F}$. UC3843 (Texas Instruments, Dallas, TX, USA) is selected to regulate the buck/boost circuit while the UCC25600 (Texas Instruments, Dallas, TX, USA) is adopted to regulate the $L L C$ resonant circuit.

Figure 6 illustrates the experiments of the presented converter at $V_{\text {in }}=18 \mathrm{~V}$ and the rated power. Since $V_{i n}=18 \mathrm{~V}<V_{d c}=72 \mathrm{~V}$, the buck/boost converter is operated at a boost operation. Therefore, $Q_{1}$ is on and $Q_{2}$ is controlled by the duty cycle modulation. Figure 6a shows the experimental waveforms of $v_{\mathrm{Q} 2, g}, i_{L f}, i_{\mathrm{Q} 2}$ and $i_{D 2}$. When $Q_{2}$ is on or off, the $i_{L f}$ equals $i_{Q 2}$ or $i_{D 2}$. Figure $6 \mathrm{~b}$ provides the test results of the input voltage $V_{i n}$, dc bus voltage $V_{d c}$, the gate voltage $v_{Q 2, g}$ and leg voltage $v_{a b}$. The duty cycle of $Q_{2}$ equals $0.75, V_{d c}>V_{i n}$ (boost operation) and the leg voltage $v_{a b}$ is a square voltage. Figure $6 c$ gives the primary-side experimental waveforms of the $L L C$ resonant circuit at full load. As the switching frequency is close to the resonant frequency, $v_{C r}$ and $i_{L r}$ are sinusoidal waveforms and $v_{a b}$ is a square waveform. Since the half-bridge $L L C$ is controlled in the second stage, the $v_{C r}$ contains a DC voltage value $\left(v_{C r, d c}=V_{d c} / 2\right)$. Figure $6 \mathrm{~d}$ provides the secondary side currents and load voltage at full load. The output voltage is regulated at $12 \mathrm{~V}$ and the load current $I_{0}=42 \mathrm{~A}$. No serious reverse recovery current is observed on the rectifier diodes $D_{o 1}$ and $D_{o 2}$. In the same manner, Figure 7 illustrates the experiments at $V_{\text {in }}=65 \mathrm{~V}$ and the rated power conditions. Since $V_{i n}=65 \mathrm{~V}<V_{d c}=72 \mathrm{~V}$, the duty cycle of $Q_{2}$ is calculated as 0.1 . The measured waveforms $v_{Q 2, g}, i_{L f}, i_{Q 2}$ and $i_{D 2}$ are shown in Figure 7a. The experimental waveforms $V_{i n}, V_{d c}, v_{Q 2, g}$ and $v_{a b}$ are illustrated in Figure $7 \mathrm{~b}$. The experimental waveforms of the resonant converter are provided in Figure $7 \mathrm{c}, \mathrm{d}$. Since $V_{d c}=72 \mathrm{~V}$ by the buck/boost converter for both $V_{\text {in }}=18 \mathrm{~V}$ and $65 \mathrm{~V}$, it can be seen that the measured waveforms of the resonant converter under $V_{\text {in }}=18 \mathrm{~V}$ (Figure $6 \mathrm{c}, \mathrm{d}$ ) and $V_{\text {in }}=65 \mathrm{~V}$ (Figure $7 \mathrm{c}, \mathrm{d}$ ) are identical. Figures 8 and 9 show the experiments of the proposed circuit for $V_{i n}=76 \mathrm{~V}$ and $288 \mathrm{~V}$ input on the high input voltage range and rated power. When the input voltage ranges between $76 \mathrm{~V}$ and $288 \mathrm{~V}$, the buck/boost circuit is controlled at a buck operation and $Q_{2}$ is off. The duty cycle of $Q_{1}$ equals $0.95(0.25)$ at $V_{\text {in }}=76 \mathrm{~V}$ $(288 \mathrm{~V})$. The measured waveforms of $v_{Q 1, g}, i_{L f}, i_{Q 1}$ and $i_{D 1}$ at $V_{i n}=76 \mathrm{~V}$ and $288 \mathrm{~V}$ are 
illustrated in Figures $8 \mathrm{a}$ and $9 \mathrm{a}$. The buck/boost converter is operated at a buck operation and $V_{d c}$ is controlled at $72 \mathrm{~V}$ for both $V_{i n}=76 \mathrm{~V}$ and $V_{i n}=288 \mathrm{~V}$. The experiments of the resonant converter for a $76 \mathrm{~V}(288 \mathrm{~V})$ input are shown in Figure $8 c, d$ (Figure 9c,d). When $65 \mathrm{~V}<V_{\text {in }}<76 \mathrm{~V}, Q_{1}$ is on and $Q_{2}$ is off. No voltage step-up or step-down is realized on the buck/boost converter so that the DC bus voltage $V_{d c}=V_{i n}$. Under this condition, only the resonant converter is worked to regulate the load voltage. Figures 10 and 11 provide the measured waveforms of the resonant circuit at $67 \mathrm{~V}$ and $74 \mathrm{~V}$ input and the rated power. When $V_{d c}=67 \mathrm{~V}$, the resonant converter needs more voltage gain compared to $V_{d c}=72 \mathrm{~V}$ and $f_{s w}<f_{r}$. Thus, $i_{L r}$ likes a quasi-sinusoidal signal in Figure 10a and $D_{01}$ and $D_{o 2}$ are turned off at zero current switching in Figure 10b. In the same manner, the switching frequency at $V_{d c}=74 \mathrm{~V}$ shown in Figure 11 is greater than the resonant frequency in order to achieve a lower voltage gain. Figure 12 illustrates the experiments of $S_{1}$ at $V_{\text {in }}=18 \mathrm{~V}$, $67 \mathrm{~V}, 74 \mathrm{~V}$ and $288 \mathrm{~V}$. Figure 12a,b shows the experimental waveforms of $S_{1}$ under $20 \%$ load and full load at $V_{\text {in }}=18 \mathrm{~V}$ condition. In the same manner, Figure 12c,d gives the measured results of $S_{1}$ at $67 \mathrm{~V}$ input. Figure $12 \mathrm{e}$,f provides the test results of $S_{1}$ at $74 \mathrm{~V}$ input. Likewise, Figure 12g,h shows the experimental waveforms of $S_{1}$ at $288 \mathrm{~V}$ input (high input voltage range). From the test results in Figure 12, it can be seen that $S_{1}$ turns on at ZVS from a $20 \%$ load for all input voltage ranges and turns off at hard switching. Since switch $S_{2}$ possesses the same switching characteristics as $S_{1}$, it can be expected that $S_{2}$ also turns on under zero voltage from a $20 \%$ load and turns off at hard switching.

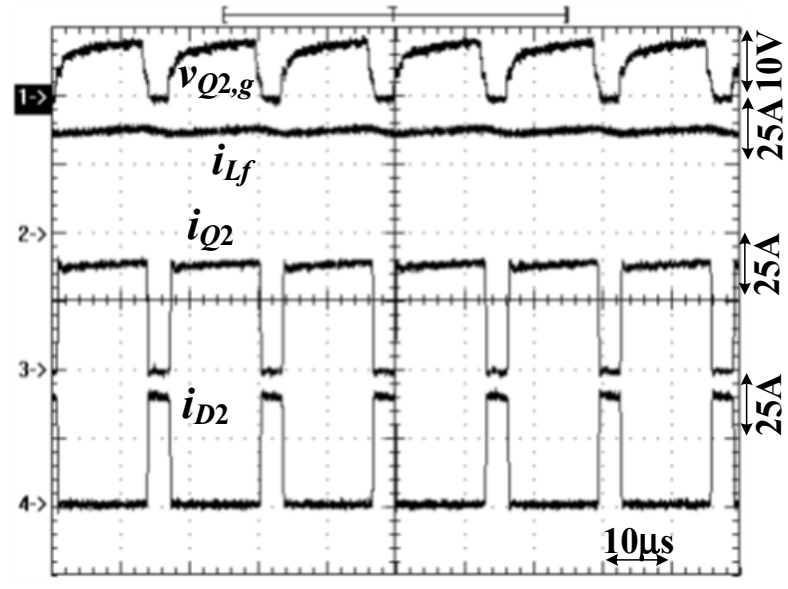

(a)

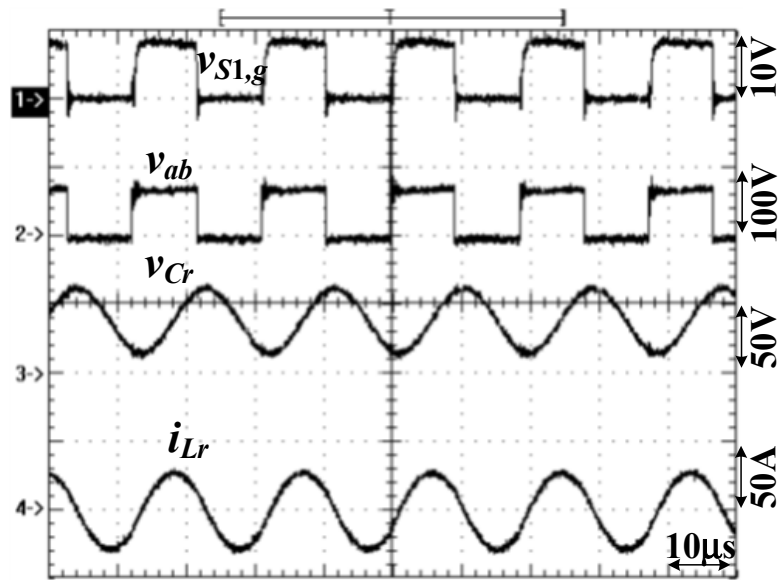

(c)

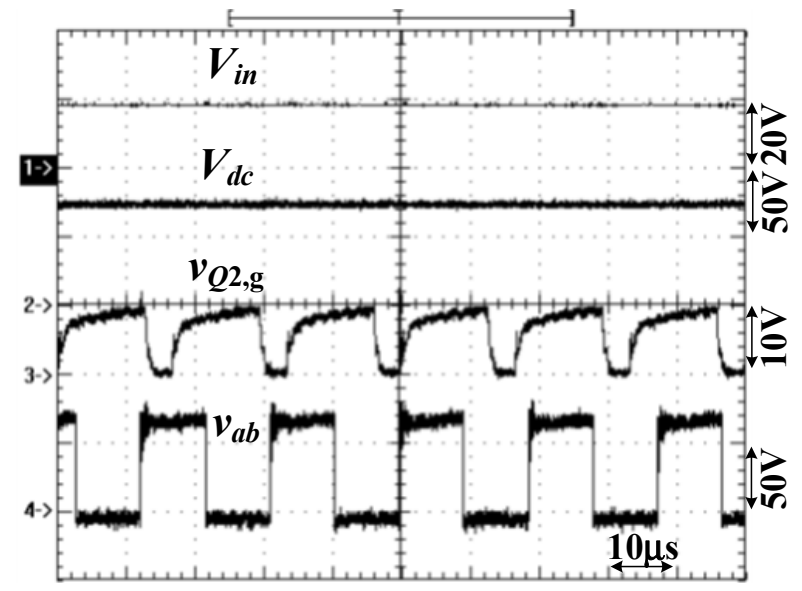

(b)

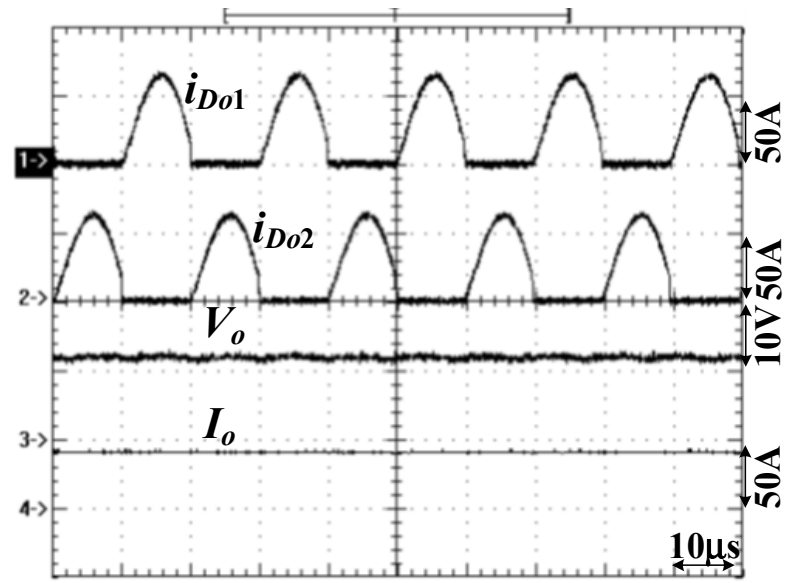

(d)

Figure 6. Measured results at $V_{i n}=18 \mathrm{~V}$ and $P_{o}=500 \mathrm{~W}(\mathbf{a}) v_{Q 2, g}, i_{L f}, i_{Q 2}$ and $i_{D 2}(\mathbf{b}) V_{i n}, V_{d c}, v_{Q 2, g}$ and $v_{a b}(\mathbf{c}) v_{S 1, g}, v_{a b}, v_{C r}$ and $i_{L r}(\mathbf{d}) i_{D o 1}, i_{D o 2}, V_{o}$ and $I_{o}$. 


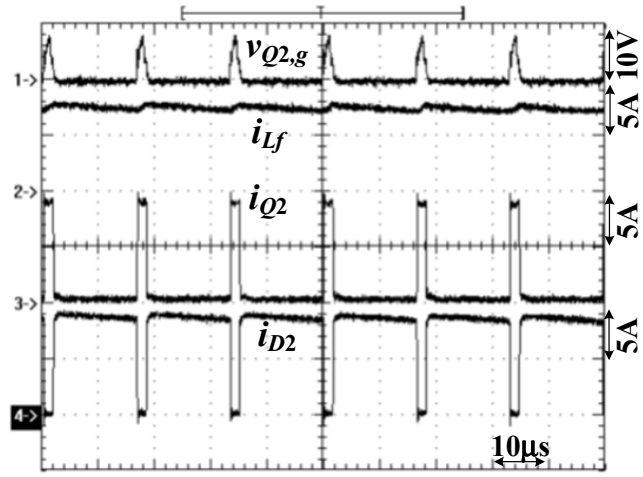

(a)

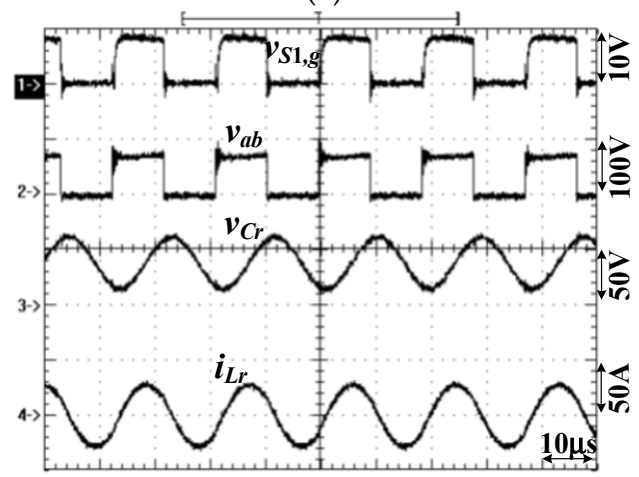

(c)

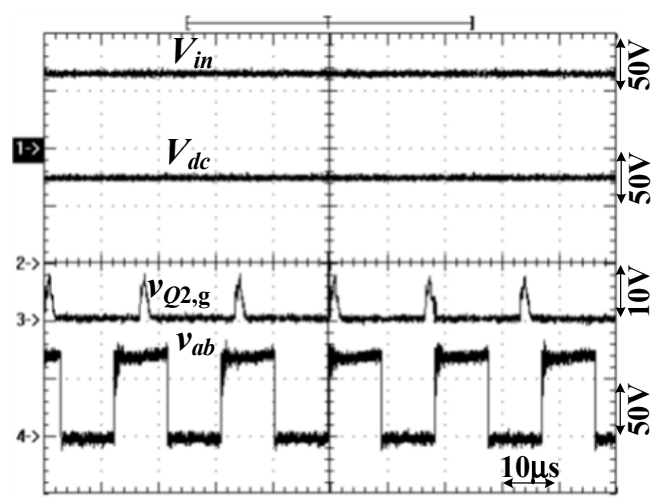

(b)

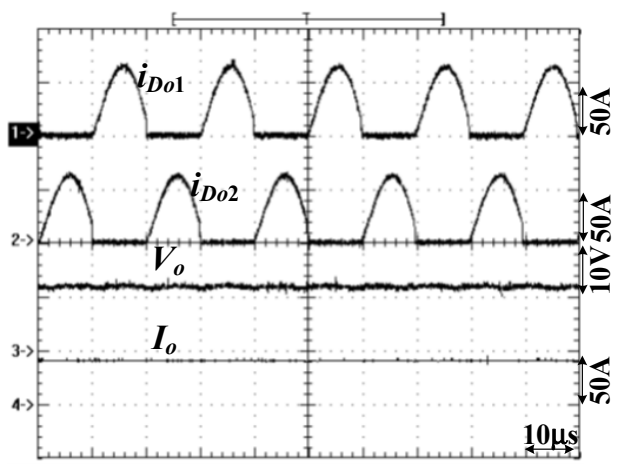

(d)

Figure 7. Measured results at $V_{i n}=65 \mathrm{~V}$ and $P_{o}=500 \mathrm{~W}(\mathbf{a}) v_{Q 2, g}, i_{L f}, i_{Q 2}$ and $i_{D 2}(\mathbf{b}) V_{i n}, V_{d c}, v_{Q 2, g}$ and $v_{a b}(\mathbf{c}) v_{S 1, g}, v_{a b}, v_{C r}$ and $i_{L r}(\mathbf{d}) i_{D o 1}, i_{D o 2}, V_{o}$ and $I_{o}$.

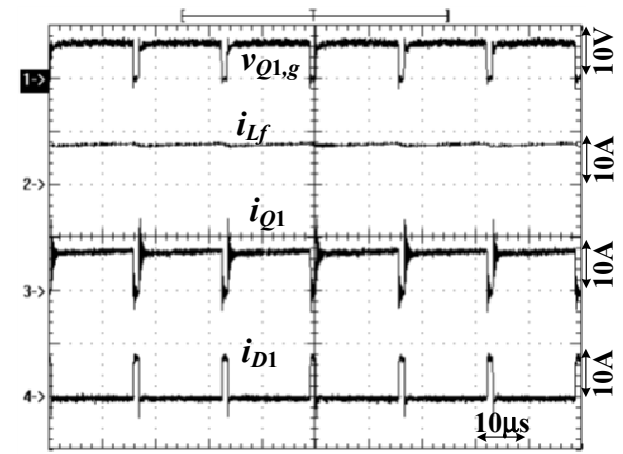

(a)

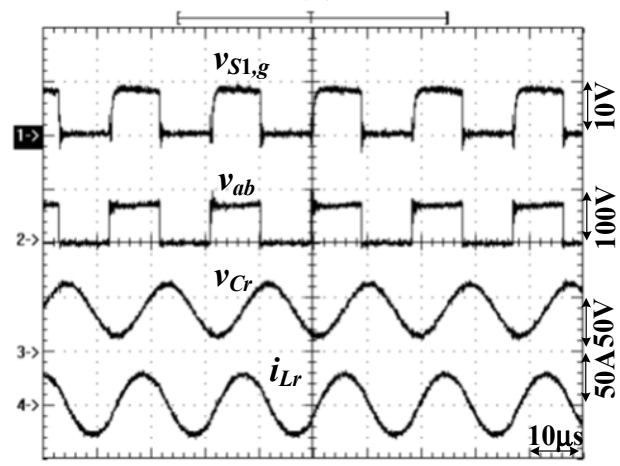

(c)

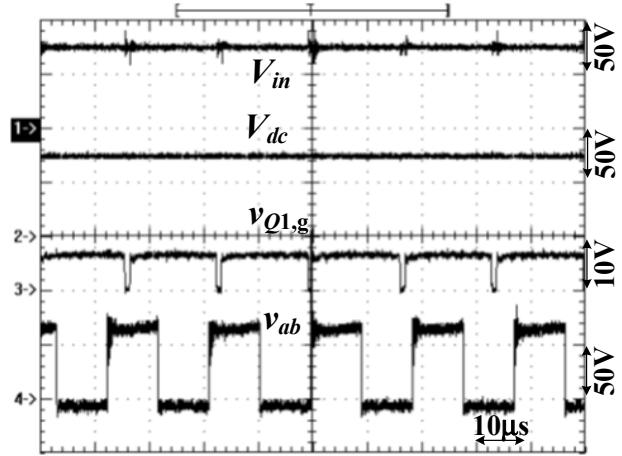

(b)

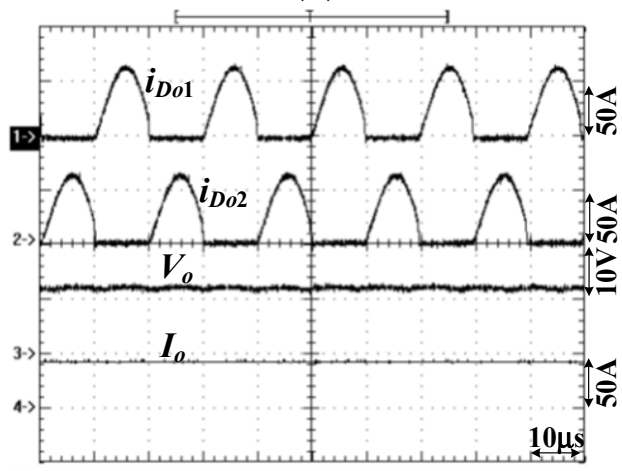

(d)

Figure 8. Measured results at $V_{i n}=76 \mathrm{~V}$ and $P_{o}=500 \mathrm{~W}(\mathbf{a}) v_{Q 1, g}, i_{L f}, i_{Q 1}$ and $i_{D 1}(\mathbf{b}) V_{i n}, V_{d c}, v_{Q 1, g}$ and $v_{a b}(\mathbf{c}) v_{S 1, g}, v_{a b}, v_{C r}$ and $i_{L r}(\mathbf{d}) i_{D o 1}, i_{D o 2}, V_{o}$ and $I_{o}$. 


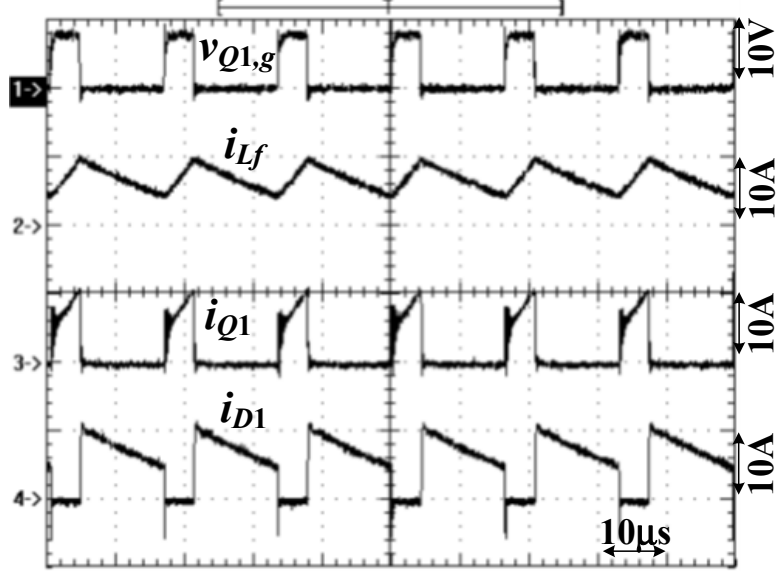

(a)

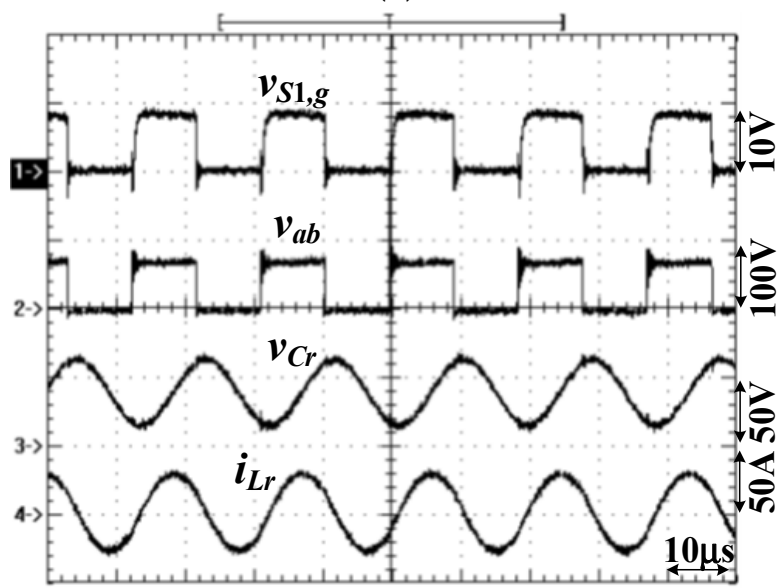

(c)

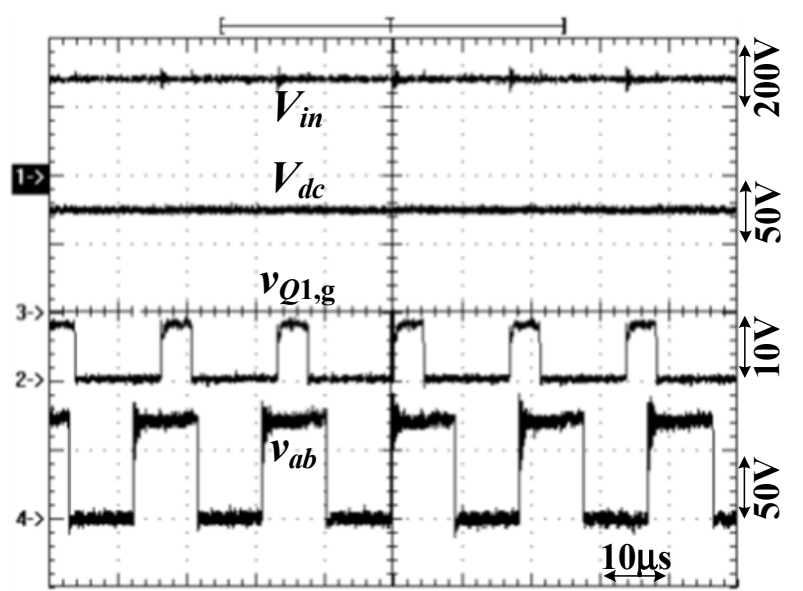

(b)

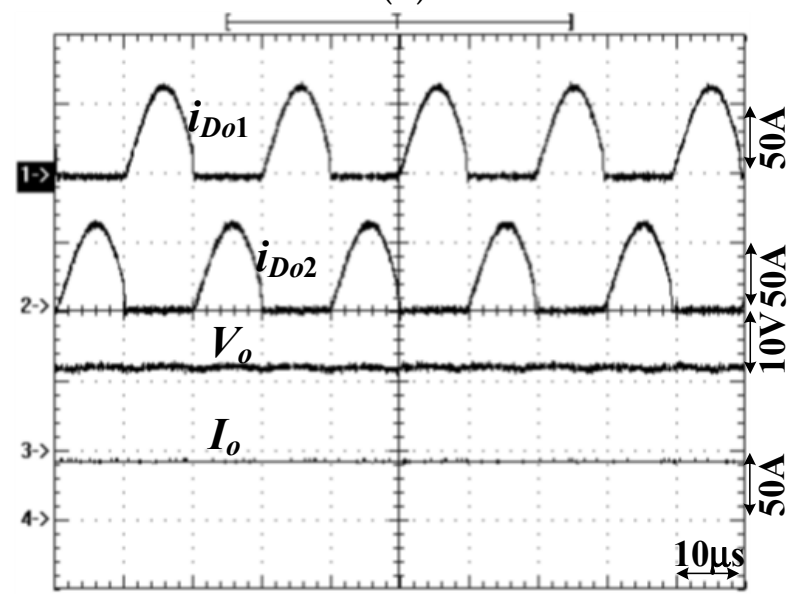

(d)

Figure 9. Measured results at $V_{i n}=288 \mathrm{~V}$ and $P_{o}=500 \mathrm{~W}(\mathbf{a}) v_{Q 1, g}, i_{L f}, i_{Q 1}$ and $i_{D 1}(\mathbf{b}) V_{i n}, V_{d c}, v_{Q 1, \mathrm{~g}}$ and $v_{a b}$ (c) $v_{S 1, g}, v_{a b}$, $v_{C r}$ and $i_{L r}(\mathbf{d}) i_{D o 1}, i_{D o 2}, V_{o}$ and $I_{o}$.

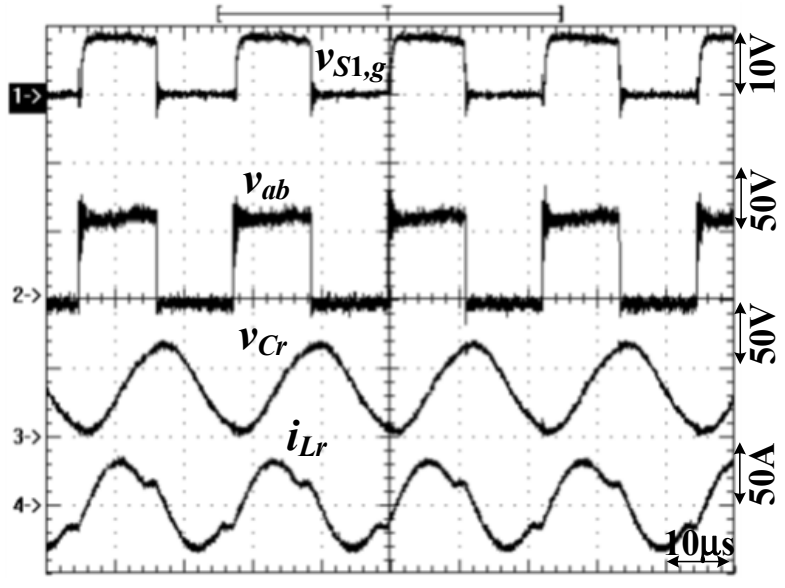

(a)

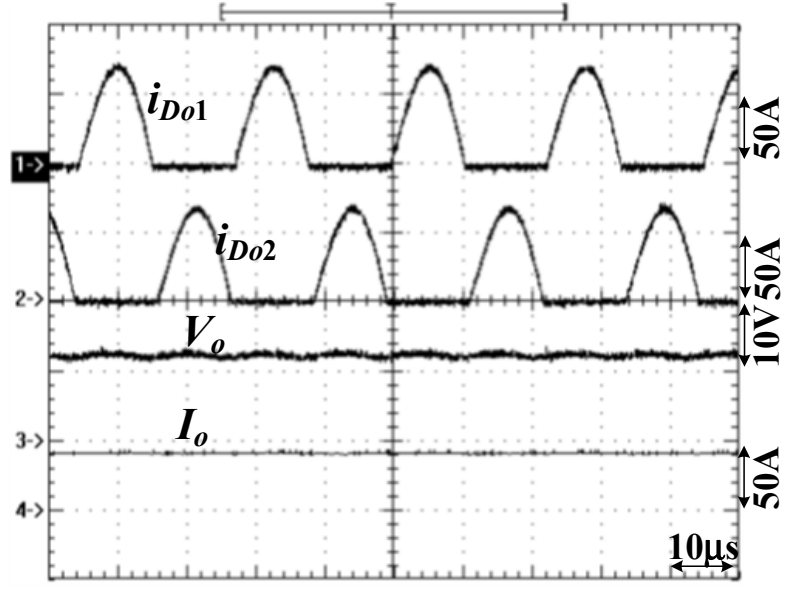

(b)

Figure 10. Measured results at $V_{i n}=67 \mathrm{~V}$ and $P_{o}=500 \mathrm{~W}(\mathbf{a}) v_{S 1, g}, v_{a b}, v_{\mathrm{Cr}}$ and $i_{L r}(\mathbf{b}) i_{D o 1}, i_{D o 2}, V_{o}$ and $I_{o}$. 


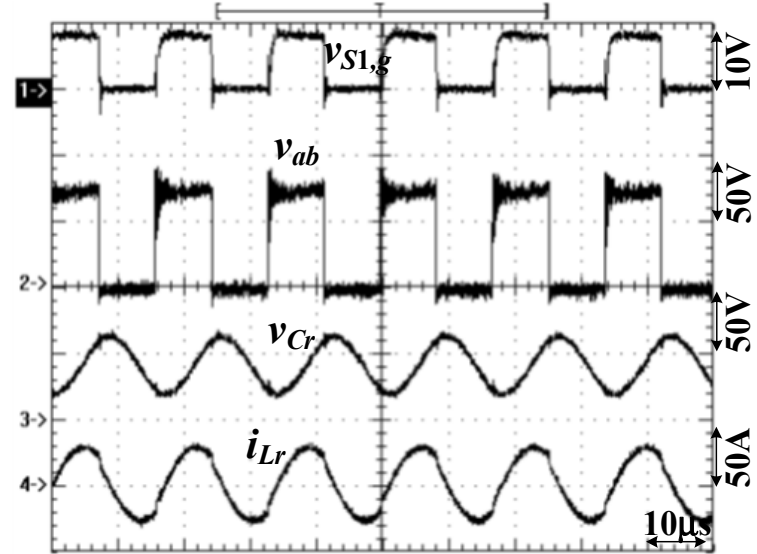

(a)

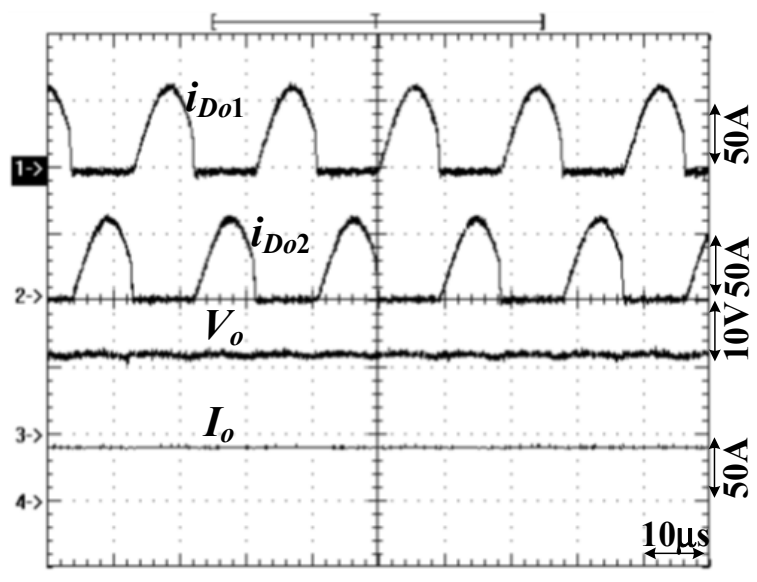

(b)

Figure 11. Measured results at $V_{i n}=74 \mathrm{~V}$ and $P_{o}=500 \mathrm{~W}(\mathbf{a}) v_{S 1, g}, v_{a b}, v_{C r}$ and $i_{L r}(\mathbf{b}) i_{D o 1}, i_{D o 2}, V_{o}$ and $I_{o}$.

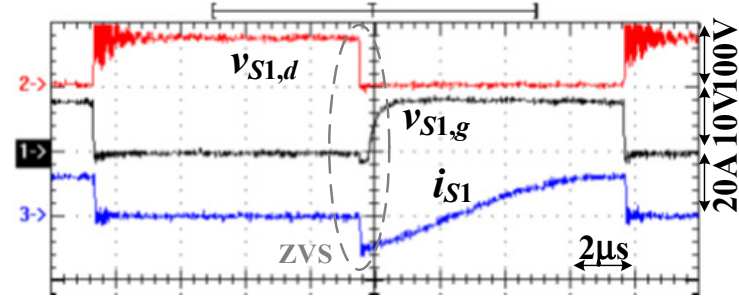

(a)

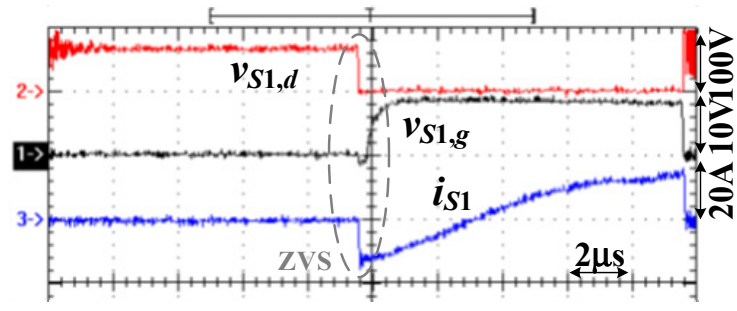

(c)

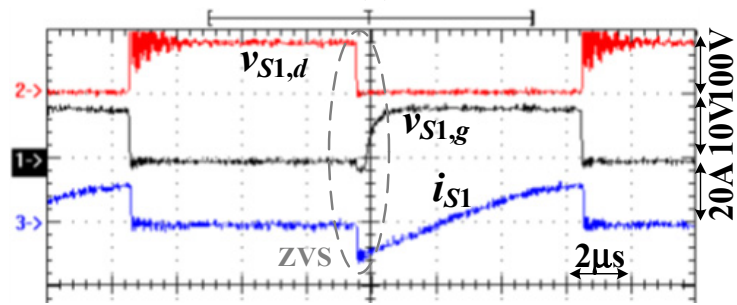

(e)

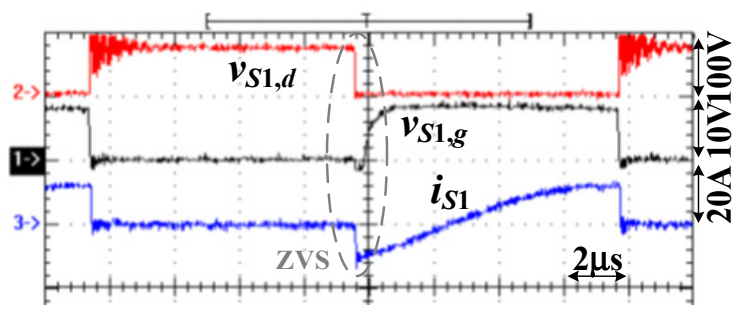

(g)

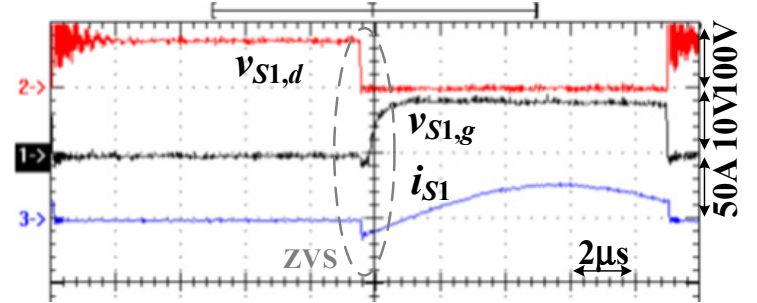

(b)

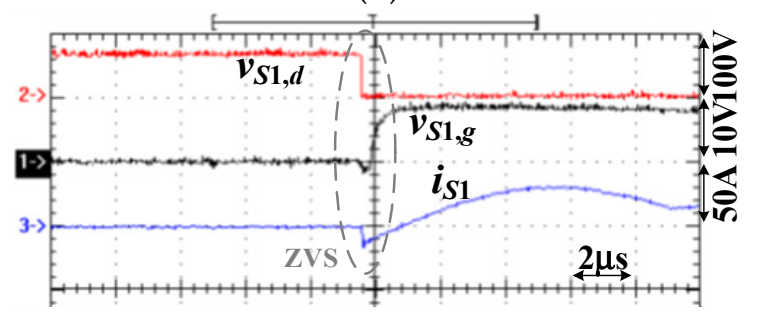

(d)

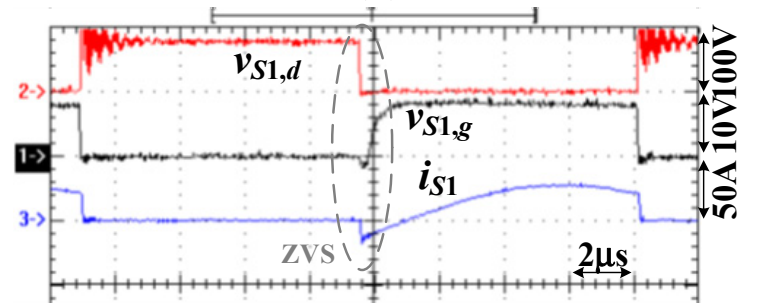

(f)

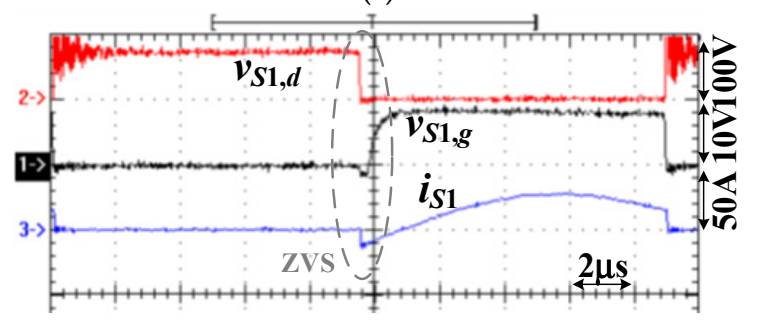

(h)

Figure 12. Experiments of switch $S_{1}$ of resonant converter at (a) $V_{\text {in }}=18 \mathrm{~V}$ and $20 \%$ power (b) $V_{\text {in }}=18 \mathrm{~V}$ and full power (c) $V_{\text {in }}=67 \mathrm{~V}$ and $20 \%$ power (d) $V_{\text {in }}=67 \mathrm{~V}$ and full power (e) $V_{\text {in }}=74 \mathrm{~V}$ and $20 \%$ power (f) $V_{\text {in }}=74 \mathrm{~V}$ and full power (g) $V_{\text {in }}=288 \mathrm{~V}$ and $20 \%$ power $(\mathbf{h}) V_{\text {in }}=288 \mathrm{~V}$ and full power. 


\section{Conclusions}

A wide input voltage (18 V 288 V) DC converter is discussed and examined for railway vehicles or for PV power conversion. To realize a 16:1 wide input voltage demand, a buck/boost circuit is used to accomplish the boost operation if $V_{\text {in }}$ is on a low input voltage range and a buck operation if $V_{\text {in }}$ is on a high input voltage range. Therefore, the DC bus voltage after the buck/boost converter is kept at a constant voltage. The resonant converter is employed on the rear-stage to achieve electric isolation and have a soft switching operation for active switches and power diodes. Since the LLC resonant converter is operated at a constant input voltage, the switching frequency variation is limited at a narrow frequency range. The performance of the studied circuit is investigated and examined through the test results.

Author Contributions: Writing — original draft, investigation, methodology, conceptualization, visualization, B.-R.L.; writing—review and editing, A.P.I.G.; validation, K.-W.W. All authors have read and agreed to the published version of the manuscript.

Funding: This research is supported by the Ministry of Science and Technology (MOST), Taiwan, under grant number MOST 108-2221-E-224-022-MY2.

Conflicts of Interest: The authors declare no conflict of interest.

\section{References}

1. Shang, C.; Liu, L.; Liu, M.; Men, S. A highly-efficient two-stage DC-DC converter with wide input voltage. In Proceedings of the 2015 IEEE International Telecommunications Energy Conference, Osaka, Japan, 18-22 October 2015; pp. 1-6.

2. Jeong, Y.; Kim, J.K.; Lee, J.B.; Moon, G.W. An asymmetric half-bridge resonant converter having a reduced conduction loss for DC/DC power applications with a wide range of low input voltage. IEEE Trans. Power Electron. 2017, 32, 7795-7804. [CrossRef]

3. Wang, P.; Zhou, L.; Zhang, Y.; Li, J.; Sumner, M. Input-parallel output-series DC-DC boost converter with a wide input voltage range, for fuel cell vehicles. IEEE Trans. Veh. Technol. 2017, 66, 7771-7781. [CrossRef]

4. Zhang, Y.; Fu, C.; Sumner, M.; Wang, P. A wide input-voltage range quasi-Z-source boost DC-DC converter with high-voltage gain for fuel cell vehicles. IEEE Trans. Ind. Electron. 2018, 65, 5201-5212. [CrossRef]

5. Yao, Z.; Xu, J. A three-phase DC-DC converter for low and wide input-voltage range application. In Proceedings of the 2016 IEEE Transportation Electrification Conference and Expo, Busan, Korea, 1-4 June 2016; pp. 208-213.

6. Li, W.; Zong, S.; Liu, F.; Yang, H.; He, X.; Wu, B. Secondary-side phase-shift-controlled ZVS DC/DC converter with wide voltage gain for high input voltage applications. IEEE Trans. Power Electron. 2013, 28, 5128-5139. [CrossRef]

7. Lin, B.R. Zero-voltage dc/dc converter with asymmetric pulse-width modulation for dc micro-grid system. Int. J. Electron. 2018, 105, 679-693. [CrossRef]

8. Lu, J.; Kumar, A.; Afridi, K.K. Step-down impedance control network resonant DC-DC converter utilizing an enhanced phase-shift control for wide-input-range operation. IEEE Trans. Ind. Appl. 2018, 54, 4523-4536. [CrossRef]

9. Wang, X.; Tian, F.; Batarseh, I. High efficiency parallel post regulator for wide range input DC-DC converter. IEEE Trans. Power Electron. 2008, 23, 852-858. [CrossRef]

10. Lin, B.R. Series resonant converter with auxiliary winding turns: Analysis, design and implementation. Int. J. Electron. 2018, 105, 836-847. [CrossRef]

11. Wu, H.; Wan, C.; Sun, K.; Xing, Y. A high step-down multiple output converter with wide input voltage range based on quasi two-stage architecture and dual-output LLC resonant converter. IEEE Trans. Power Electron. 2015, 30, 1793-1796. [CrossRef]

12. Lin, B.R. Novel ZVS DC-DC converter with low current ripple for light rail transit. Int. J. Electron. 2019, 106, 567-580. [CrossRef]

13. Xiao, Z.; Wang, Y.; Zhao, G.; Xu, Y.; Lu, C.; Hu, W. A power-switch thermal limiting technique for current-mode monolithic DC-DC converters. Int. J. Electron. Commun. 2019, 111, 152797. [CrossRef] 